\title{
Characterization of Muscarinic Cholinergic Receptors in the Brains of Copper-deficient Rats ${ }^{\mathbf{1}}$
}

\author{
JUDITH R. FARRAR, ${ }^{2}$ WAYNE HOSS, ${ }^{3}$ ROBERT M. HERNDON, AND MARTA KUZMIAK \\ Center for Brain Research, University of Rochester School of Medicine and Dentistry, Rochester, New York 14642
}

\begin{abstract}
In order to assess a possible role for copper as a regulator of muscarinic receptors in vitro, the receptor was characterized in rats made copper deficient by a dietary regimen. In forebrain regions there was a decrease in both the affinity of the receptors for $\left[{ }^{3} \mathrm{H}\right]-1$-quinuclidinyl benzilate and the density of receptors in the copper-deficient animals compared with control animals. Copper treatment in vitro of homogenates from deficient animals did not reverse the in vivo effects on antagonist binding but, rather, decreased receptor occupancy and ligand affinity in a manner similar to copper treatment of control homogenates. Minimally deficient rats displayed very similar changes in receptor properties compared with the more severely deficient animals. Minimal copper deficiency produced robust effects on the binding of agonists, increasing $\mathrm{ID}_{50}$ and derived dissociation constants. The addition of copper to the assay medium caused an apparent reversal of the In vivo effect of copper deficiency on agonist binding, decreasing $\mathrm{ID}_{50}$ and derived dissociation constants to values near those observed with homogenates from normal animals in the presence of copper. Since copper deficiency has dramatic effects on both receptor number and the binding of agonists to muscarinic receptors in the central nervous system, it is suggested that copper, because of its ability to form complexes with some proteins, may have an endogenous role in the regulation of the receptor.
\end{abstract}

Transition and heavy metals affect muscarinic receptors by inhibiting the binding of antagonists at higher concentrations (Aronstam et al., 1978). The effect on antagonist binding is apparently reversible and competitive, with $\mathrm{Hg}^{2+}$ having the greatest inhibitory potency $\left(I_{50}=10^{-7} \mathrm{M}\right)$. At lower concentrations, metals such as $\mathrm{Cu}^{2+}, \mathrm{Cd}^{2+}, \mathrm{Pb}^{2+}$, and $\mathrm{Zn}^{2+}$ increase agonist binding without affecting antagonist binding (Aronstam et al., 1978). Since there is no further metal-induced increase in agonist binding after pretreatment with $\mathrm{N}$-ethylmaleimide, sulfhydryl groups are probably involved in the ability of lower concentrations of metals to increase agonist binding.

We have recently reported that the in vitro addition of low con-

Received June 18, 1984; Revised August 31, 1984;

Accepted August 31, 1984

'We are indebted to Lynn Arenella for the histological preparation of the tissue. The work reported here was supported by National Institutes of Health Grant DA 01851, a grant from the Council for Tobacco Research, National Institutes of Health Trainee Grant GM 07141 (J. R. F.), and National Institutes of Health Research Scientist Career Development Award DA 00010 (W. H.).

${ }^{2}$ Present address: Department of Ophthalmology, University of Rochester School of Medicine and Dentistry, Rochester, NY 14642.

${ }^{3}$ To whom correspondence should be addressed. centrations of $\mathrm{Cu}$ to regional homogenates of rat brain alters the binding of both agonists and antagonists to muscarinic cholinergic receptors (Farrar and Hoss, 1984). The major effects of the treatment are a decrease in apparent receptor number, an increase in affinity for quinuclidinyl benzilate (QNB), and an increase in agonist affinity. $\mathrm{A} \mathrm{Cu}$-induced shift in receptor subtypes toward higher affinity receptors is suggested. Cu treatment also differentiates between muscarinic receptors of brainstem and forebrain-regions of low and high Cu content, respectively (Farrar and Hoss, 1984). The concentration of $\mathrm{Cu}$ required to produce these effects is a small fraction of the total Cu normally present in brain.

To test more directly the hypothesis that $\mathrm{Cu}$ is an endogenous regulator of the muscarinic receptor, the receptor was characterized in the brains of Cu-deficient rats. We report here that Cu deficiency produces significant decreases in both the apparent number of receptors and the affinity of the receptors for agonists.

\section{Materials and Methods}

\section{Materials}

Male and fernale albino rats of the Sprague-Dawley strain were purchased from the Charles River Breeding Laboratories. Carbamylcholine (CCH) chloride, gallamine triethiodide, and cupric chloride were obtained from Aldrich Chemical Co., K \& K Laboratories, and Mallinckrodt, Inc., respectively. Scintanalyzed grade toluene was acquired from Fisher Chemical Co. The nitric and perchloric acids used for the preparation of atomic absorption samples were ACS grade (Baker-analyzed) from VWR. The copper standard solution for atomic absorption spectrophotometry was purchased from Ventron (Alfa Division). $\left[{ }^{3} \mathrm{H}\right]$-Quinuclidinyl benzilate (QNB)-1-isomer, specific activity 32 to $44 \mathrm{Ci} / \mathrm{mmol}$, was obtained from Amersham. Radiolabeled samples were counted with a Searle model 300 liquid scintillation counter at an efficiency of $30 \%$

\section{Animals}

Binding assays and metal determinations were performed on tissue from male Sprague-Dawley albino rats. All animals examined were sacrificed at 42 days. The following groups were bred and compared.

\section{Normal}

These animals were raised on standard laboratory rat chow containing approximately 44 to $52 \mu \mathrm{g}$ of $\mathrm{Cu} / \mathrm{gm}$ of diet.

\section{Deficient}

Females from the $\mathrm{F} 1$ generation of normal Sprague-Dawley females were weaned at 19 days and separated randomly into control and deficient groups. The deficient population was placed on copper test diet (US Biochemical Corp.) containing less than $0.2 \mu \mathrm{g}$ of $\mathrm{Cu} / \mathrm{gm}$ of diet. These females were mated to normal males over a 48 -hr period at 8 to 9 weeks of age (minimum weight, $180 \mathrm{gm}$ ). During the mating and gestation period the animals were maintained on test diet supplemented with $2 \mu \mathrm{g}$ of $\mathrm{Cu} / \mathrm{gm}$ of diet. This level of copper was necessary to prevent resorption of the fetuses. The F2 generation was weaned at 19 days and maintained on copper test diet until sacrifice. 
TABLE I

Copper levels of isolated brain rogions of normal, control, deficient, and two populations of minimally deficient (MCF2, D14) rats

Values are expressed as micrograms of copper per gram of dry weight of the isolated brain area. Errors are reported as the standard error of the mean of two to four experiments in which each value was determined in quadruplicate.

\begin{tabular}{|c|c|c|c|c|c|}
\hline & \multirow[b]{2}{*}{$\begin{array}{l}\text { Normal } \\
4^{a}\end{array}$} & \multirow[b]{2}{*}{$\begin{array}{c}\text { Control } \\
3\end{array}$} & \multirow[b]{2}{*}{$\begin{array}{c}\text { Deficient } \\
3\end{array}$} & \multicolumn{2}{|c|}{ Minimally Deficient Region } \\
\hline & & & & $\begin{array}{c}\mathrm{D} 14 \\
3\end{array}$ & $\begin{array}{c}\text { MCF2 } \\
2\end{array}$ \\
\hline Cerebellum & $13.3 \pm 0.57$ & $12.2 \pm 0.53$ & $4.5 \pm 0.53$ & $9.1 \pm 0.78$ & $9.9 \pm 0.86$ \\
\hline Brainstem & $14.1 \pm 0.46$ & $13.8 \pm 0.91$ & $3.9 \pm 0.31$ & $12.0 \pm 1.04$ & $13.8 \pm 0.58$ \\
\hline Hippocampus & $34.0 \pm 1.84$ & $29.3 \pm 2.32$ & $10.7 \pm 0.79$ & $21.5 \pm 1.76$ & $19.0 \pm 1.95$ \\
\hline Striatum & $34.5 \pm 1.11$ & $31.5 \pm 1.83$ & $9.6 \pm 0.91$ & $19.8 \pm 1.99$ & $21.4 \pm 2.91$ \\
\hline
\end{tabular}

a Number of experiments (2 to 4$)$.

TABLE ॥

The binding of $\left[^{3} \mathrm{H}\right]-1-\mathrm{QNB}$ to regional homogenates prepared from the brains of normal, control, copper-deficient, and minimally deficient rats and incubated in the presence and absence of $3 \mu \mathrm{M}$ copper

Data are presented for direct binding assays using [ $\left.{ }^{3} \mathrm{H}\right]-1-\mathrm{QNB}$ as described under "Materials and Methods." Errors are reported as the standard error of the mean of two to four experiments $(N)$, in which each value was determined in triplicate. No error indicates that only one experiment was performed.

\begin{tabular}{lccc}
\hline & \multirow{3}{c}{$\begin{array}{c}\text { Apparent Number of Binding Sites } \\
\text { (pmol/mg of protein) }\end{array}$} \\
\cline { 3 - 4 } & & No Added Cu & $+3 \mu \mathrm{M} \mathrm{Cu}$ \\
\hline Normal & & & \\
$\quad$ Hippocampus & 4 & $2.70 \pm 0.01$ & $1.40 \pm 0.02$ \\
$\quad$ Striatum & 4 & $3.60 \pm 0.03$ & $2.40 \pm 0.01$ \\
$\quad$ Cortex & 4 & $2.10 \pm 0.02$ & $1.05 \pm 0.01$ \\
$\quad$ Forebrain & 4 & $2.45 \pm 0.01$ & $1.30 \pm 0.01$ \\
Control & & & \\
$\quad$ Hippocampus & 3 & $2.73 \pm 0.02$ & $1.35 \pm 0.03$ \\
$\quad$ Striatum & 3 & $3.50 \pm 0.02$ & $2.45 \pm 0.02$ \\
$\quad$ Cortex & 3 & $2.14 \pm 0.06$ & $0.90 \pm 0.01$ \\
$\quad$ Forebrain & 2 & $2.26 \pm 0.02$ & $1.11 \pm 0.03$ \\
Deficient & & & \\
$\quad$ Hippocampus & 3 & $1.50 \pm 0.02$ & $0.80 \pm 0.01$ \\
$\quad$ Striatum & 3 & $1.50 \pm 0.02$ & $0.80 \pm 0.00$ \\
$\quad$ Cortex & 3 & $0.90 \pm 0.02$ & $0.45 \pm 0.01$ \\
$\quad$ Forebrain & 2 & $1.50 \pm 0.05$ & $0.75 \pm 0.02$ \\
$\quad$ Minimally Deficient (D14) & 3 & $1.60 \pm 0.00$ & $1.00 \pm 0.03$ \\
$\quad$ Forebrain & & & \\
Minimally Deficient (D14)- & 1 & 2.25 & 1.50 \\
$\quad$ Reversed Forebrain & & & \\
\hline & & & \\
\hline
\end{tabular}

\section{Control}

The control females from the F1 generation described above were placed on copper test diet supplemented with 46 to $48 \mu \mathrm{g}$ of Cu/gm of diet to approximate the copper level of the standard laboratory rat chow. The mating parameters were the same as for the deficient populations. Pups were weaned at 19 days and maintained on the supplemented diet until sacrifice.

\section{Minimally deficient}

Two groups of minimally deficient animals were bred.

MCF2. These animals represented the F2 generation of females maintained on copper test diet supplemented with 16 to $18 \mu \mathrm{g}$ of Cu/gm of diet. Pups were weaned at 19 days of age and kept on the minimally supplemented diet until use.

D14. This population was bred to determine the development of minima deficiency within one generation. Normal pregnant Sprague-Dawley females were placed on the minimally supplemented copper test diet at day 14 of gestation. Pups weaned at 19 days of age were maintained on this diet until sacrifice at 42 days. Control animals were born to females placed on the

\section{TABLE III}

The binding of $\left[^{3} \mathrm{H}\right]-1-Q N B$ to regional homogenates prepared from the brains of normal, control, copper-deficient, and minimally deficient rats and incubated in the presence and absence of $3 \mu \mathrm{M}$ copper

The values for $K_{a}$ were determined using data obtained from direct binding assays with $\left[{ }^{3} \mathrm{H}\right]-1$-QNB as described under "Materials and Methods." Errors are reported as the standard error of the mean of two to four experiments $(N)$, in which each value was determined in triplicate. No error indicates that only one experiment was performed.

\begin{tabular}{lccc}
\hline & \multicolumn{3}{c}{ Dissociation Constant for QNB Binding $\left(\kappa_{\alpha} \times 10^{-10}\right)$} \\
\cline { 3 - 4 } & & No Added Cu & $+3 \mu \mathrm{M} \mathrm{Cu}$ \\
\hline Normal & & & \\
$\quad$ Hippocampus & 4 & $0.53 \pm 0.04$ & $0.44 \pm 0.06$ \\
$\quad$ Striatum & 4 & $0.53 \pm 0.08$ & $0.43 \pm 0.05$ \\
$\quad$ Cortex & 4 & $0.49 \pm 0.07$ & $0.45 \pm 0.07$ \\
$\quad$ Forebrain & 4 & $0.59 \pm 0.08$ & $0.37 \pm 0.03$ \\
Control & & & \\
$\quad$ Hippocampus & 3 & $0.54 \pm 0.08$ & $0.42 \pm 0.04$ \\
$\quad$ Striatum & 3 & $0.52 \pm 0.05$ & $0.43 \pm 0.01$ \\
$\quad$ Cortex & 3 & $0.49 \pm 0.03$ & $0.33 \pm 0.07$ \\
$\quad$ Forebrain & 2 & $0.62 \pm 0.04$ & $0.38 \pm 0.04$ \\
Deficient & & & \\
$\quad$ Hippocampus & 3 & $2.15 \pm 0.25$ & $1.63 \pm 0.10$ \\
$\quad$ Striatum & 3 & $1.82 \pm 0.20$ & $1.33 \pm 0.30$ \\
$\quad$ Cortex & 3 & $1.44 \pm 0.30$ & $1.32 \pm 0.23$ \\
$\quad$ Forebrain & 2 & $1.07 \pm 0.12$ & $0.56 \pm 0.08$ \\
Minimally Deficient (D14) & 3 & $0.91 \pm 0.14$ & $0.34 \pm 0.02$ \\
$\quad$ Forebrain & & & \\
Minimally Deficient (D14)- & 1 & 0.60 & 0.36 \\
$\quad$ Reversed Forebrain & & & \\
\hline
\end{tabular}

control test diet (containing 46 to $48 \mu \mathrm{g}$ of Cu/gm of diet) at day 14 of gestation. These animals were maintained on the control diet from weaning until use.

\section{Brain metal content}

Metal content was determined in six specific brain regions (cerebellum, brainstem, midbrain, cortex, hippocampus, and striatum) as well as forebrain Forebrain encompasses tissue anterior to the superior colliculus. Brain tissue was prepared for analysis using the wet digestion technique of Harrison et al. (1968). Briefly, this involved drying the tissue at $110^{\circ} \mathrm{C}$ for $12 \mathrm{hr}$ followed by digestion in $1: 1$ concentrated $\mathrm{HNO}_{3}: \mathrm{HClO}_{4}$ at $200^{\circ} \mathrm{C}$. Digestion was allowed to proceed until the white fumes of $\mathrm{HClO}_{4}$ were evolved, and the samples were water clear. Copper content was determined by atomic absorption spectrophotometry using a Perkin Elmer model 372 atomic absorption spectrophotometer at a wavelength of $324.8 \mathrm{~nm}$ and a slit width of $0.7 \mathrm{~nm}$. Acetylene and air were used as fuel and oxidizer, respectively. Digested samples were diluted as necessary with deionized water and measured against a reagent black. Metal recovery, as measured by the addition of two different amounts of $\mathrm{Cu}$ to tissue digests, was virtually $100 \%$ for all brain areas. 


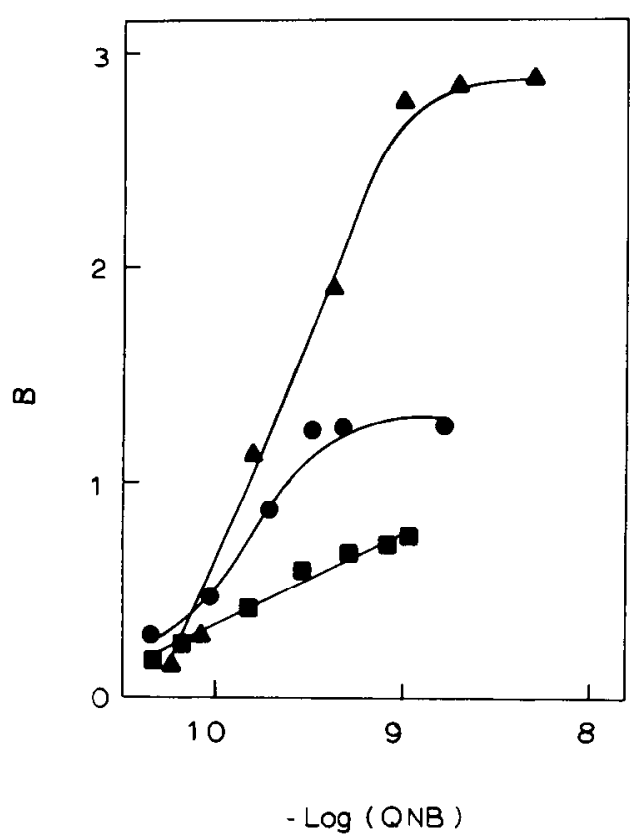

Figure 1. Log-dose curves for a typical experiment depicting the specific binding $(B)$ of $\left.{ }^{3} \mathrm{H}\right] \mathrm{QNB}$ to crude synaptosomal membranes from copperdeficient cortex in the presence $(\square)$ and absence $(\Theta)$ of $3 \mu \mathrm{M}$ copper in vitro. The binding curves are shown in comparison to the specific binding of $\left[{ }^{3} \mathrm{H}\right]$ QNB in normal cortex in the absence of added medium copper $(\boldsymbol{\Delta})$. Binding is expressed as picomoles per milligram of protein. The curves were drawn according to derived binding parameters.

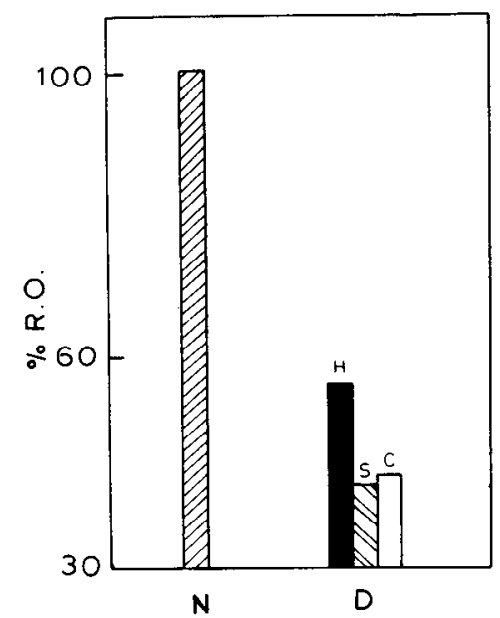

Figure 2. Receptor occupancy (R.O.) in hippocampal $(H)$, striatal $(S)$, and cortical $(C)$ homogenates prepared from copper-deficient $(D)$ animals expressed as a percentage of the specific QNB binding of normal and control $(N)$ homogenates. The bars represent the composites of four experiments.

\section{Neural membrane preparation}

Crude membrane preparations from rat hippocampus, striatum, and cortex as well as from forebrain and brainstem were used in the various binding assays. The tissue was homogenized in $10 \mathrm{vol}$ of $40 \mathrm{~mm}$ sodium/potassium phosphate buffer, $\mathrm{pH} 7.4$, and centrifuged at $3,000 \times \mathrm{g}$ for $10 \mathrm{~min}$. The supernatant was then centrifuged at $60,000 \times g$ for $30 \mathrm{~min}$. The resulting pellet was suspended in $40 \mathrm{~mm}$ sodium/potassium phosphate buffer, $\mathrm{pH}$ 7.4. Protein content was determined by a modification of the method of Lowry et al. (1951). Aliquots of the suspension were frozen rapidly in liquid nitrogen and stored at $-20^{\circ} \mathrm{C}$. Binding studies showed these samples to remain stable and comparable to fresh homogenates for at least 4 weeks.

\section{Binding assays}

The muscarinic binding assays utilized a modification of the filtration assay developed by Yamamura and Snyder (1974) which uses the binding of QNB,

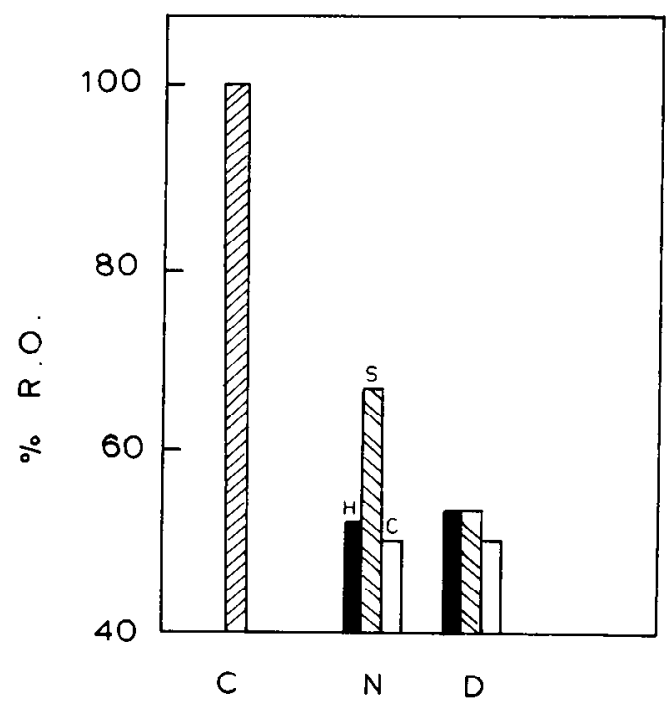

Figure 3. Receptor occupancy (R.O.) in the presence of $3 \mu \mathrm{M}$ copper in vitro expressed as a percentage of the specific binding of $\left[{ }^{3} \mathrm{H}\right] \mathrm{MNB}$ in the absence of added medium copper. Bars show percentage of binding for homogenates prepared from normal $(N)$ and copper-deficient $(D)$ hippocampus $(H)$, striatum $(S)$, and cortex $(C)$, and represent the mean of four experiments

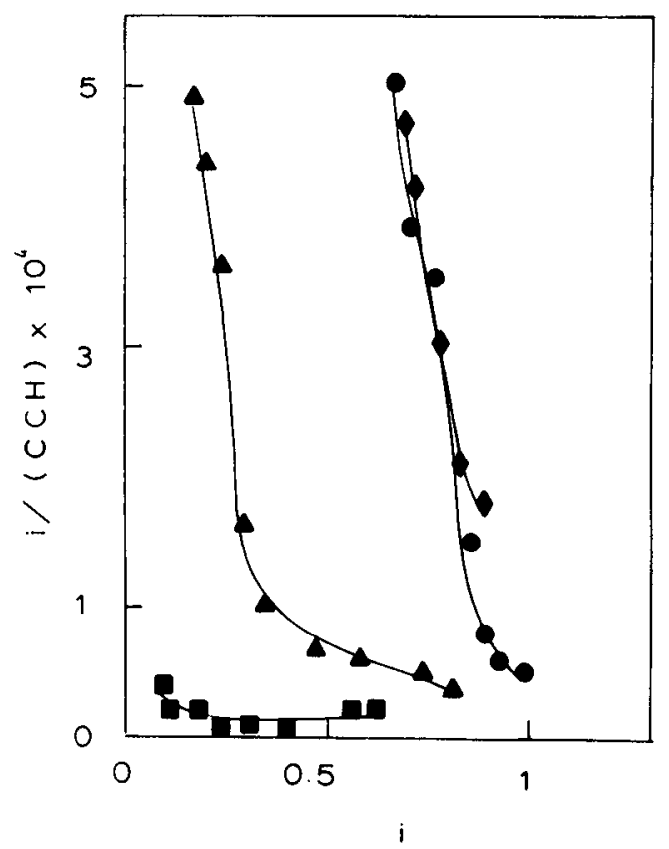

Figure 4. Scatchard plots of the binding of $\mathrm{CCH}$ to forebrain synaptosomal preparations from normal and minimally deficient (D14) rats. Curves are shown for $\mathrm{CCH}$ binding in the presence $(\boldsymbol{O})$ and absence $(\boldsymbol{\Delta})$ of $1 \mu \mathrm{M}$ copper for normal animals and in the presence $(\boldsymbol{\bullet})$ and absence $(\boldsymbol{D})$ of copper for deficient animals. The data are representative of single experiments. Mean values of derived constants are presented in Table IV.

a specific and potent muscarinic antagonist. Suspensions containing $60 \mu \mathrm{g}$ of protein $/ \mathrm{ml}$ for forebrain and $30 \mu \mathrm{g}$ of protein $/ \mathrm{ml}$ for brainstem, $40 \mathrm{mM}$ sodium/potassium phosphate buffer, $\mathrm{pH} 7.4$, and various concentrations of $\left[{ }^{3} \mathrm{H}\right]-\mathrm{I}-\mathrm{QNB}$ were incubated at room temperature for $1 \mathrm{hr}$. Control samples contained a 1000 -fold excess of unlabeled QNB relative to the highest concentration of $\left[{ }^{3} \mathrm{H}\right]-1-\mathrm{QNB}$. Samples were filtered with suction through Whatman GF/B glass fiber filters and were washed twice with $5 \mathrm{ml}$ of cold phosphate buffer. The filters were placed in Nalge scintillation bags with 4 $\mathrm{ml}$ of Triton-toluene scintillation fluid. The bags were then placed in scintillation vials and held for at least $12 \mathrm{hr}$ before counting. Specific binding was defined as the difference between the values obtained in the absence and presence of excess unlabeled QNB.

Indirect binding was determined by the ability of the ligand of choice to 
TABLE IV

The binding of $\mathrm{CCH}$ to forebrain preparations from normal, control, and minimally deficient rats incubated in the presence and absence of $1 \mu \mathrm{M}$ copper

Data are presented for indirect binding assays using the ability of $\mathrm{CCH}$ to displace $\left[{ }^{3} \mathrm{H}\right]-1$-QNB from the receptors as described under "Materials and Methods." $K_{H}$ and $K_{L}$ refer to high and low affinity constants, respectively; $\alpha$ denotes the proportion of high affinity receptors. Errors are reported as the standard error of the mean of two to four experiments $(N)$, in which each value was determined in quadruplicate.

\begin{tabular}{|c|c|c|c|c|c|}
\hline & $N$ & $\mathbb{I}_{s o}(\mu \mathrm{M})$ & $\alpha$ & $K_{H}(\mu \mathrm{M})$ & $K_{L}(\mu \mathrm{M})$ \\
\hline \multicolumn{6}{|l|}{ No added $\mathrm{Cu}$} \\
\hline \multicolumn{6}{|l|}{$\mathrm{CCH}$} \\
\hline Normal & 4 & $5.69 \pm 0.21$ & $0.42 \pm 0.08$ & $0.26 \pm 0.02$ & $40.14 \pm 10.24$ \\
\hline \multicolumn{6}{|c|}{ Minimally Deficient } \\
\hline D14 & 3 & $29.89 \pm 3.04$ & $0.41 \pm 0.02$ & $0.48 \pm 0.02$ & $118.50 \pm 8.21$ \\
\hline MCF2 & 3 & $29.42 \pm 1.34$ & $0.39 \pm 0.01$ & $0.32 \pm 0.02$ & $113.52 \pm 7.18$ \\
\hline Normal & 4 & $1.00 \pm 0.14$ & $0.70 \pm 0.06$ & $0.28 \pm 0.05$ & $34.42 \pm 5.82$ \\
\hline Control & 2 & $0.69 \pm 0.05$ & $0.67 \pm 0.06$ & $0.24 \pm 0.03$ & $25.31 \pm 0.15$ \\
\hline \multicolumn{6}{|c|}{ Minimally Deficient } \\
\hline D14 & 3 & $0.51 \pm 0.05$ & $0.71 \pm 0.01$ & $0.34 \pm 0.04$ & $28.97 \pm 5.33$ \\
\hline MCF2 & 3 & $0.96 \pm 0.02$ & $0.61 \pm 0.03$ & $0.19 \pm 0.03$ & $35.77 \pm 1.35$ \\
\hline
\end{tabular}

displace 50 pM [ $\left.{ }^{3} \mathrm{H}\right]-1-\mathrm{QNB}$ from the receptor. Experimental conditions were carefully determined and strictly maintained. Each sample contained approximately $10 \mathrm{pM}$ receptors $(4.0 \mu \mathrm{g} / \mathrm{ml}$ of protein for forebrain and $5.4 \mu \mathrm{g} / \mathrm{ml}$ of protein for brainstem) in a final volume of $20 \mathrm{ml}$. This receptor concentration had no significant effect on the ligand-induced inhibition of $\left[{ }^{3} \mathrm{H}\right] \mathrm{QNB}$ binding as determined experimentally. Addition of receptor homogenate to individual sample tubes was staggered such that the incubation time for each tube was precisely $90 \mathrm{~min}$. Binding parameters for $\left[{ }^{3} \mathrm{H}\right] \mathrm{QNB}$ were determined directly by Scatchad analysis, and parameters for $\mathrm{CCH}$ were determined indirectly by competition with $\left[{ }^{3} \mathrm{H}\right] \mathrm{QNB}$ according to a two-site model as described elsewhere (Ellis and Hoss, 1980).

The effect of $\mathrm{Cu}$ on muscarinic binding properties in vitro was determined by including $3 \mu \mathrm{M} \mathrm{CuCl}_{2}$ in the incubation medium for direct binding assays and $1 \mu \mathrm{M} \mathrm{CuCl}$ in the medium for indirect studies. The concentration of $\mathrm{Cu}$ was unbuffered and thus represents total added $\mathrm{Cu}$.

\section{Nucleic acid analysis}

The RNA and DNA content of whole brains from normal and copperdeficient rats was determined using the simple fluorometric assay developed by Prasad et al. (1972). This method exploits the increase in fluorescence of ethidium bromide $(\mathrm{EBr})$ upon complexing with nucleic acids.

The brains were rinsed in deionized water, blotted, and weighed prior to homogenization in nucleic acid buffer $(0.1 \mathrm{M}$ Tris and $0.1 \mathrm{M} \mathrm{Nacl}), \mathrm{pH} 7.4$ Samples were diluted 1:100 with buffer. Sample tubes containing $1 \mathrm{ml}$ of $\mathrm{EBr}(20 \mu \mathrm{g} / \mathrm{ml}), 0.9 \mathrm{ml}$ of buffer, and $0.1 \mathrm{ml}$ of homogenate were read against a reagent blank at fluorometer settings of $365-\mathrm{nm}$ excitation and $590-\mathrm{nm}$ emission wavelengths. Care was taken to permit as little time lapse as possible between homogenate preparation, sample addition, and measure ment to prevent any degradative loss of RNA. Two sets of assay tubes were examined. The fluorescence of the first represented total nucleic acid content. Each tube of the second set received $0.02 \mathrm{ml}$ of RNase $(20 \mathrm{mg} / \mathrm{ml}$; type IIIA from bovine pancreas, Sigma Chemical Co.), and the entire set was incubated at $50^{\circ} \mathrm{C}$ for $1 \mathrm{hr}$. This incubation ensured complete hydrolysis of the RNA. The fluorescence measurement, therefore, represented DNA content only. The RNA content of the tissue was determined by the difference of the two readings. Determinations of DNA and RNA were compared to standard curves prepared immediately preceding each experiment. The sensitivity of the method was checked periodically using recovery experiments with the addition of known concentrations of DNA and RNA to tissue homogenates. Recovery of added nucleic acids was virtually $100 \%$ for both DNA and RNA.

\section{Histology}

Two deficient rats were anesthetized with Chloropent and perfused with a $1 \%$ paraformaldehyde $/ 2 \%$ glutaraldehyde $/ 1 \%$ acrolein fixative in phosphate buffer. After fixation in situ for a minimum of $1 \mathrm{hr}$, the brains were removed and blocks of white matter were cut from the centrum semiovale. Following a 1 -hr postfixation in $1 \%$ buffered osmium tetroxide, the tissue was stained en bloc with uranyl acetate in $50 \%$ ethanol, dehydrated, and embed ded in Poly 812. Sections were cut using a diamond knife, retrieved on uncoated copper grids, and stained with lead citrate. Histological examination employed a Zeiss 10 electron microscope.

\section{Results}

Brain metal content. Metal levels in isolated brain regions of normal, control, and deficient animals (as described under "Materials and Methods") are shown in Table I. Control and normal animals were similar in general appearance, weight gain, and motor activity. Statistical analyses revealed no significant differences between the two groups for either brain metal content or mortality rate. Copper deprivation during development decreased brain copper levels by 65 to $75 \%$ in all regions examined. The deprived animals showed a number of observable abnormalities including subnormal weight, loss of hair, incoordination of the hindlimbs, and increased mortality.

Two populations of minimally deficient animals-MCF2 and D14were also bred as described under "Materials and Methods." Brain copper content for both populations is included in Table I. The decrease in regional copper levels showed greater variation in the minimally deficient animals relative to the deficient rats. The copper content of the forebrain structures hippocampus, striatum, and cortex decreased by 27 to $37 \%$ in minimally deficient animals as compared to a 7 to $25 \%$ copper loss in non-forebrain regions. Animals of both MCF2 and D14 groups showed fewer coat problems, increased weight, and decreased mortality rate relative to deficient rats. Problems in coordination were diminished, but physical activity remained lower than for the normal group. Statistical analyses revealed no significant differences between MCF2 and D14 for either brain metal content or mortality rate.

Antagonist binding. The differential effect of minimal $\mathrm{Cu}$ deprivation on brain Cu content is interesting and in accord with the reported Cu sensitivity of forebrain. Studies performed in this laboratory have shown forebrain muscarinic receptors to be particularly susceptible to the effects of in vitro Cu addition (Farrar and Hoss, 1984). The binding data shown in Tables $I I$ and III indicate that forebrain muscarinic receptors are also sensitive to $\mathrm{Cu}$ deprivation in vivo. Cudeficient preparations of hippocampus, striatum, cortex, and whole forebrain consistently showed significant decreases $(P<0.001)$ in ligand affinity and in the number of apparent binding sites relative to the normal or control groups. Binding curves for normal and deficient cortex are presented in Figure 1. These curves, as well as those in Figure 4, present data from single experiments delineating representative trends. The shift of the deficient plot down and to the right was evident in all preparations assayed.

The deficiency-induced decline in receptor number is clearly indicated in Figure 2, which presents receptor occupancy in deficient preparations as a percentage of QNB binding in the normal group. (Statistical analyses revealed no differences in the binding behavior of the normal and control groups.) Specific binding decreased by 


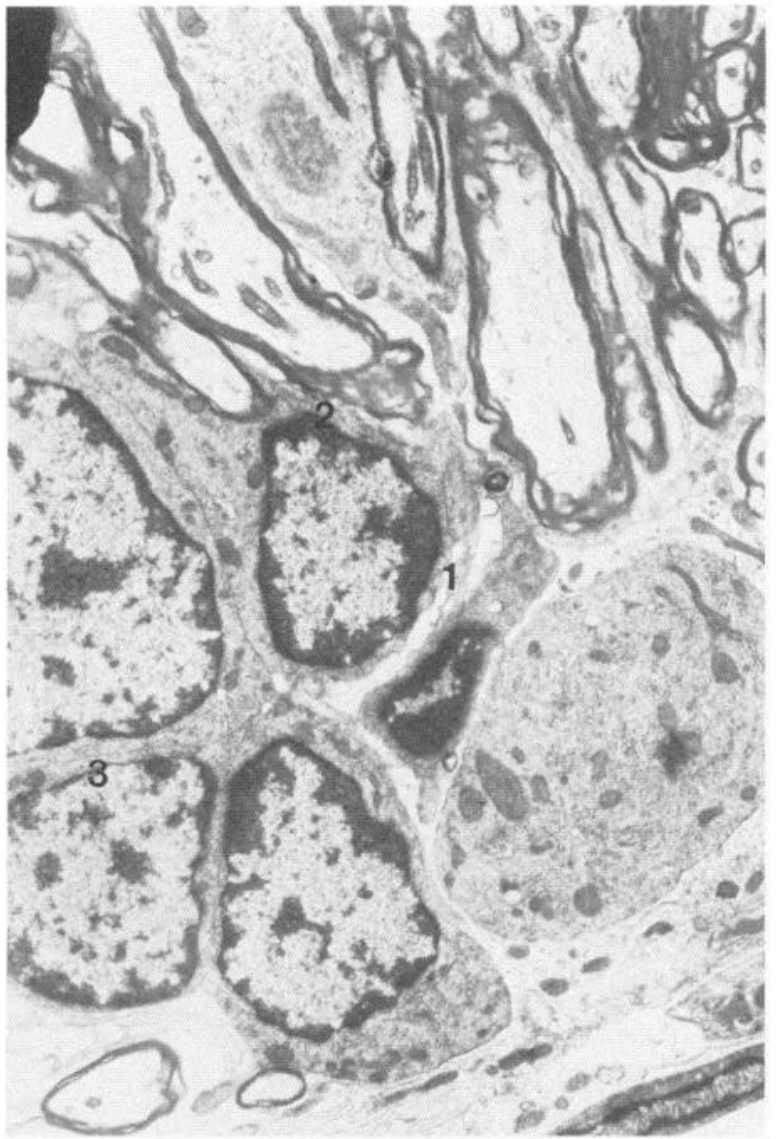

Figure 5. Abnormal white matter in copper-deficient rat brain, from the cerebellum of a 35-day-old rat. This field demonstrates the amorphous bubbling (1) and membrane fragmentation (2) affecting certain oligodendrocytes in copper-deficient brain. Normal-appearing oligodendrocytes (3) are also shown in this section. Magnification $\times 18,000$.

44,58 , and $57 \%$ in the deficient hippocampal, striatal, and cortical homogenates, respectively. Specific binding in the deficient forebrain preparation decreased by $40 \%$.

The effects of adding $3 \mu \mathrm{M}$ Cu to a deficient preparation are included in Figure 1. It is apparent that the addition of $\mathrm{Cu}$ to the incubation medium did not reverse the effects of the deficiency but decreased receptor occupancy and ligand affinity in a manner similar to $\mathrm{Cu}$ treatment of normal and control homogenates (see Tables II and III for specific values). Similarities between the addition of $3 \mu \mathrm{M}$ $\mathrm{Cu}$ to normal and deficient homogenates are obvious in Figure 3 , which depicts receptor occupancy following $\mathrm{Cu}$ addition as a percentage of QNB binding in homogenates with no added $\mathrm{Cu}$. The apparent number of binding sites decreased by $33 \%$ in normal striatal homogenates and by 45 to $50 \%$ in all other preparations. The decline in the number of QNB recognition sites was significant $(P<0.001)$ in all cases.

Use of minimally deficient animals for agonist assays necessitated examination of QNB binding in minimally deficient preparations relative to deficient homogenates. Although minimally deficient rats were similar to the control and normal animals in mortality rate and general appearance, the binding parameters of the minimally deficient group were comparable to those of the deficient preparations as shown in Tables II and III.

Nucleic acid content. Alterations in specific binding can occur from changes in cell number as well as from changes affecting the binding site itself. The possibility that the decline in apparent binding sites in deficient preparations was due to a decrease in the number of cells bearing QNB sites was addressed by nucleic acid analyses. The respective DNA and RNA contents expressed as micrograms

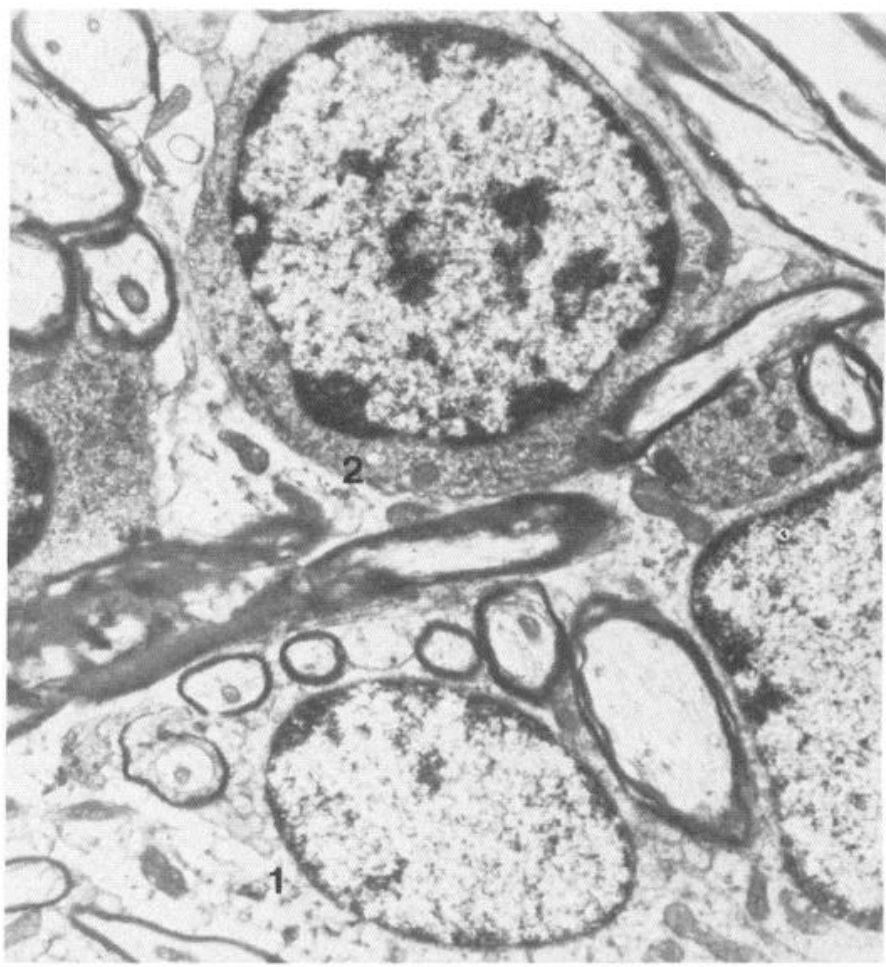

Figure 6. Abnormal white matter in copper-deficient rat brain, from the cerebellum of a 35-day-old rat. Astrocytic swelling (1) is evident in this section. The oligodendrocyte included in the field shows signs of increased membrane fragility (2). Magnification $\times 24,000$.

per milligram of wet weight were $1.3 \pm 0.2$ and $1.2 \pm 0.1$ in normal homogenates and $1.2 \pm 0.2$ and $1.0 \pm 0.2$ in deficient preparations. These figures are in accord with those reported for rat forebrain by Prasad et al. (1972). The differences between the normal and deficient groups were not statistically significant.

Reversibility. The possibility of reversing the diet-induced developmental copper deficiency in vivo was of interest. One rat from the minimally deficient D14 group was placed on normal rat chow at 28 days of age. At 49 days, this animal showed normal weight, a normal-appearing coat, and increased physical activity. Results presented in Tables II and III allow comparison of the binding parameters for normal, minimally deficient, and deficiency-reversed forebrains in the presence and absence of added copper. However, these results should be treated with caution since they are derived from only one animal.

Agonist binding. Scatchard plots for the binding of the muscarinic agonist, $\mathrm{CCH}$, to forebrain receptors from normal and minimally deficient D14 animals are presented in Figure 4. Binding parameters determined according to a two-site model are shown in Table IV. Forebrain homogenates prepared from the D14 animals showed significant $(P<0.001)$ increases in the values of $\mathrm{ID}_{50}, K_{H}$, and $K_{L}$ relative to the normal and control groups. The percentage of binding sites in the high affinity state $(\alpha)$ was unchanged by developmental Cu deprivation.

The addition of $1 \mu \mathrm{M} \mathrm{Cu}$ to the incubation medium appeared to reverse the effects of $\mathrm{Cu}$ deprivation on agonist binding, in contrast to the effects of $\mathrm{Cu}$ treatment on antagonist binding. However, in both cases, receptors from Cu-deprived animals actually responded to $\mathrm{Cu}$ treatment in a manner comparable to that of receptors from normal and control groups. In the presence of medium $\mathrm{Cu}$, the Scatchard plot and the derived binding data for the minimally deficient forebrain homogenates approximated those of the normal and control preparations following in vitro $\mathrm{Cu}$ treatment. The change in all parameters upon the addition of $\mathrm{Cu}$ to the medium was significant $(P<0.001)$ for all experimental groups. 


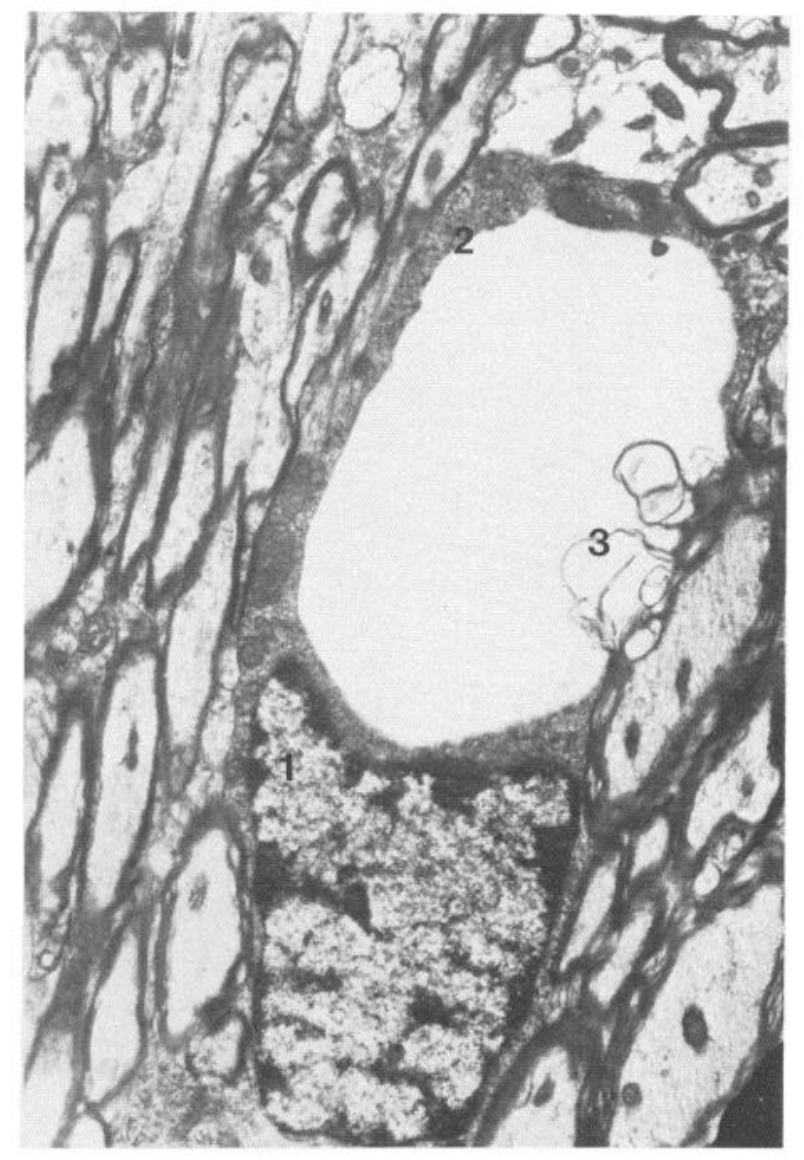

Figure 7. Abnormal capillary in copper-deficient rat brain, from the cerebellum of a 35-day-old rat. The endothelial cell appears thickened (1), and the capillary wall shows increased fragility (2). Myelin leakage into the capillary space is evident (3). Magnification $\times 16,000$.

Histology. Histological examination of the brain tissue of 35-dayold Cu-deficient rats found overt changes in white matter and indicators of vascular and dendritic disruption. Inspection of the perfused brain revealed increased translucence of myelin. Electron microscopic study of the tissue disclosed the formation of amorphous bubbles within oligodendrocytes and partial dissolution and swelling of astrocytes (Figs. 5 and 6, respectively). Figure 7 provides evidence of the capillary fragility of Cu-deficient brain. Rupture of the capillary with protrusion of myelin from the surrounding tissue into the capillary space suggests weakness of the capillary wall. We have never seen such rupture in normal animals. Electron microscopic examination of the neuropil of $\mathrm{Cu}$-deficient rats also revealed dendritic effects including swelling and membrane fragmentation with formation of membranous whorls (Fig. 8).

\section{Discussion}

The experiments reported here used a nutritionally controlled animal model to examine a role for copper in the modulation of brain muscarinic binding parameters. Second generation animals born to females maintained on copper-restricted diets showed symptoms of severe copper deficiency. The behavioral and morphological anomalies noted for these animals are comparable to those reported for other cases of dietary or genetic copper deficiency (Everson et al. 1968; Carlton and Kelly, 1969; DiPaolo et al., 1974; Keen and Hurley, 1976; O'Dell et al., 1976; McMurray, 1980). Neurological abnormalities included ataxia, akinesia, tremor, seizure postures, and hyperirritability. Alterations in white and gray matter and evidence of vascular dysfunction were disclosed upon histological examination of the copper-deficient brain tissue. Histological examination of postmortem tissue from patients with Menke's syndrome, a human

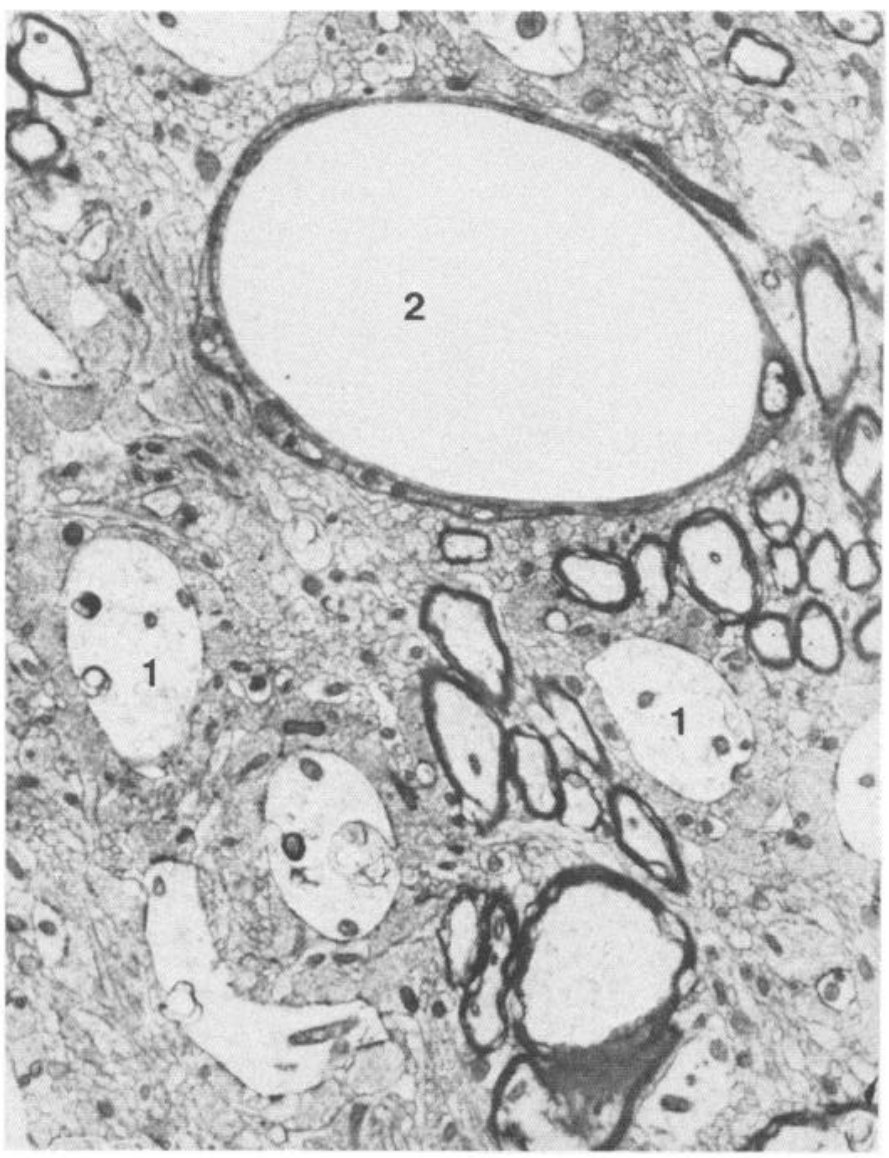

Figure 8. Neuropil of copper-deficient rat brain from the cortex of a 35 day-old rat showing swollen dendrites (1). The capillary (2) in this picture is normal in appearance. Magnification $\times 20,000$.

genetic disorder involving failure of intestinal absorption of copper, has also shown degenerative changes that affect the composition of white matter and neuropil (Danks et al., 1972). Vascular disorders have been described previously for these patients as well as for copper-deficient rats (DiPaolo et al., 1974). Lack of adequate copper intake is known to cause arterial defects due to diminished crosslinking of elastin and collagen. Lysyl-oxidase, a copper metalloenzyme, is the key enzyme in the cross-linking process.

Since histological examination of Cu-deficient rat brain revealed abnormalities of white matter and myelin, lipid analyses (Reese and Hoss, 1983) were performed in some animals. No significant differences in the phospholipid or cerebroside content or fatty acid composition due to $\mathrm{Cu}$ deficiency could be demonstrated. Although a decrease in phospholipid docosahexaenoic acid and a compensatory appearance of an unknown but highly unsaturated fatty acid were observed, these minor changes in unsaturated fatty acid distribution were also found in the brains of Cu-supplemented control animals (data not shown). Thus, these effects are due to dietary changes other than $\mathrm{Cu}$ deficiency and cannot account for the observed alterations in muscarinic receptors since the latter effects were not observed in control animals.

The biochemical effects of copper deficiency on several central neurotransmitter systems have been described by Feller et al. (1982). The authors noted a preferential reduction of muscarinic and dopaminergic receptors in forebrain regions. No change was reported for $\beta$-adrenergic receptor binding. The selective nature of the effect of copper deficiency suggests that the lesion is receptor specific. Receptor modifications secondary to lipid and/or vascular disruption presumably reflect widespread involvement of all neurotransmitter systems. Our results are compatible with the conclusions of Feller et al. (1982). We note specific effects on muscarinic systems, 
including decreased receptor density, in forebrain areas, regions of relatively high copper content in normal rats. These regions appear to be more sensitive to copper deficiency than low copper areas such as brainstem. Results with marginally deficient animals indicated involvement of forebrain structures only. It is particularly interesting that binding parameters for the minimally deficient animals were comparable to data obtained with copper-deficient rats despite the lack of deficiency symptoms (e.g., hair loss, hindlimb incoordination, tail extension).

Consideration of the myriad effects of copper deficiency raises the possibility that receptor decline is secondary to changes in cellularity. Diffuse neuronal damage and gliosis have been associated with the genetic copper deficiency of Menke's syndrome (Danks et al., 1972). However, nucleic acid analyses performed on the copper-deficient brain tissue described here showed no change in the number of cells bearing QNB recognition sites. Neuron death was negated by the constancy of total nucleic acid content (DNA and RNA). A change in the proportion of neurons and glial cells (e.g., by gliosis) was contradicted by the lack of change in the RNA:DNA ratio. Glial cell proliferation with concomitant loss of RNArich neurons results characteristically in a reduction in the nucleic acid ratio (Rappoport et al., 1969). Examination of the neuropil of copper-deficient rats by electron microscopy indicated some dendritic disruption involving swelling and increased membrane fragility (Fig. 8). Such changes could account for the reduction of receptor sites in the presence of normal cell ratios. Light microscopic autoradiography with $\left[{ }^{3} \mathrm{H}\right] \mathrm{QNB}$ has indicated a preferential localization of muscarinic receptors on dendrites rather than cell bodies (Kuhar and Yamamura, 1975).

Developmental copper deprivation resulted in specific decreases in muscarinic ligand affinity in addition to the decrement in binding site number. Preparations from deficient animals showed marked decreases in receptor affinity toward the potent muscarinic antagonist, QNB, and agonist, $\mathrm{CCH}$. The large increase in $\mathrm{ID}_{50}$ for $\mathrm{CCH}$ was correlated with significant increases in both $K_{H}$ and $K_{L}$. These results are contrary to those of Feller et al. (1982), who noted no change in receptor affinity toward QNB or oxotremorine. (Agonist binding parameters, however, were not addressed.) It is likely that these differences reflect variations in the nutritional model and/or experimental conditions.

Two generalizations emerge from the studies of copper effects on muscarinic binding parameters: (1) copper deprivation during development induces an alteration in receptor density in vivo that is not correctable by the addition of copper in vitro, and (2) the receptors of copper-deficient homogenates are capable of responding to copper in vitro in normal manner.

It appears, moreover, that the decrease in agonist-binding affinity is due to the lack of $\mathrm{Cu}$ in the deficient animals. $\mathrm{Cu}^{2+}$ is a sulfhydryl ligand with a propensity for forming stable square planar complexes, allowing $\mathrm{Cu}^{2+}$ to bridge more than one protein. The data presented here are compatible with the notion that endogenous $\mathrm{Cu}$ may participate in the dimer-tetramer equilibrium corresponding to low and high agonist affinity states of the receptor, respectively, as suggested by Avissar et al. (1983). Thus, endogenous Cu may be involved in interactions between receptors or between a receptor and some other membrane protein.

\section{References}

Aronstam, R. S., L. G. Abood, and W. Hoss (1978) Influence of sulfhydryl reagents and heavy metals on the functional state of the muscarinic acetylcholine receptor in rat brain. Mol. Pharmacol. 14: 575-586.

Avissar, S., G. Amitai, and M. Sokolovsky (1983) Oligomeric structure of muscarinic receptors is shown by photoaffinity labeling: Subunit assembly may explain high- and low-affinity agonist states. Proc. Natl. Acad. Sci. U. S. A. $80: 15-159$.

Carlton, W. W., and W. A. Kelly (1969) Neural lesions in offspring of female rats fed a copper-deficient diet. J. Nutr. 97: 42-52.

Danks, D. M., P. E. Campbell, B. J. Stevens, V. Maynes, and E. Cartwright (1972) Menke's kinky hair syndrome: An inherited defect in copper absorption ith widespread effects. Pediatrics 50: 188-201.

DiPaolo, R. V., J. N. Kanfer, and P. M. Newberne (1974) Copper deficiency and the central nervous system. Myelination in the rat: Morphological and biochemical studies. J. Neuropathol. Exp. Neurol. 33: 226-236.

Ellis, J., and W. Hoss (1980) Analysis of regional variations in the affinities of muscarinic agonists in the rat brain. Brain Res. 193: 189-198.

Everson, G. J., R. E. Shrader, and T. Wang (1968) Chemical and morpholog ical changes in the brains of copper-deficient guinea pigs. J. Nutr. 96: $115-125$

Farrar, J. R., and W. Hoss (1984) Effects of copper on the binding of agonists and antagonists to muscarinic receptors in rat brain. Biochem. Pharmacol. 3.3. $2849-2856$

Feller, D. J., B. L. O'Dell, and D. B. Bylund (1982) Alterations in neurotransmitter receptor binding in discrete areas of the copper-deficient rat brain. J. Neurochem. 38: 519-524.

Harrison, W. W., M. G. Netsky, and M. D. Brown (1968) Trace elements in human brain: Copper, zinc, iron and magnesium. Clin. Chem. Acta 21: $55-60$.

Keen, C., and L. Hurley (1976) Copper supplementation in Quaking mutant mice: Reduced tremors and increased brain copper. Science 193: 244245.

Kuhar, M. D., and H. I. Yamamura (1975) Light autoradiographic localization of cholinergic muscarinic receptors in rat brain by specific binding of a potent antagonist. Nature 153: 560-561.

Lowry, O. H., N. J. Rosebrough, A. L. Farr, and R. J. Randall (1951) Protein measurement with the Folin phenol reagent. J. Biol. Chem. 193: 265-275.

McMurray, C. H. (1980) Copper deficiency in ruminants. Ciba Found. Symp. 79: 183-205.

O'Dell, B. L., R. M. Smith, and R. A. King (1976) Effect of copper status on brain neurotransmitter metabolism in the lamb. J. Neurochem. 26: 451455

Prasad, A. S., E. DuMouchelle, D. Konish, and D. Oberleas (1972) A simple fluorometric method for the determination of RNA and DNA in tissues. J. Lab. Clin. Med. 80: 598-602.

Rappoport, D. A., R. R. Frit7, and J. L. Myers (1969) Nucleic acids. In Handbook of Neurochemistry, A. Lajtha, ed., Vol. I, pp. 101-109. Plenum Press, New York.

Reese, J. H., and W. Hoss (1983) Activation of fluoride-stimulated adenylate cyclase by phospholipase $A_{2}$ in the caudate nucleus of the rat brain. Neurochem. Res. 8: 1059-1069.

Yamamura, H. I., and S. H. Snyder (1974) Muscarinic cholinergic binding in rat brain. Proc. Natl. Acad. Sci. U. S. A. 71: 1725-1729. 